\title{
Megalencephaly-polymicrogyria-postaxial polydactyly-hydrocephalus syndrome
}

INSERM

\section{Source}

INSERM. (1999). Orphanet: an online rare disease and orphan drug data base.

Megalencephaly-polymicrogyria-postaxial polydactyly-hydrocephalus syndrome.

ORPHA:83473

Megalencephaly-polymicrogyria-postaxial polydactyly-hydrocephalus syndrome is characterized by megalencephaly, polymicrogyria, and hydrocephalus with variable polydactyly. It has been described in six unrelated patients. Intellectual deficit or slow development is also present. The mode of inheritance of this syndrome is unknown since all cases were sporadic. 